\title{
Validation of a LC-MS/MS Multiresidue Methodology Based on a QuEChERS Approach for the Determination of Fluoroquinolones, Sulfonamides and Trimethoprim in Poultry and Porcine Kidney According to the Normative Instruction 24/2009-MAPA
}

\author{
Diego G. Rocha, ${ }^{*, a, b}$ Flavio A. Santos, ${ }^{b}$ Aline A. Gomes ${ }^{b}$ and Adriana F. Faria ${ }^{a}$ \\ ${ }^{a}$ Departamento de Química, Instituto de Ciências Exatas, Universidade Federal de Minas Gerais, \\ 31270-901 Belo Horizonte-MG, Brazil \\ ${ }^{b}$ Laboratório Nacional Agropecuário (LANAGRO-MG), Ministério da Agricultura, Pecuária e \\ Abastecimento, 33600-000 Pedro Leopoldo-MG, Brazil
}

\begin{abstract}
This work involved the validation of a multiresidue method according to the Normative Instruction 24/2009-MAPA for determining 25 analytes, among fluoroquinolones, sulfonamides and trimethoprim in samples of poultry and porcine kidney. The extraction procedure was based on a QuEChERS approach. A liquid chromatography-tandem mass spectrometry (LC-MS/MS) method was developed using the selected reaction monitoring mode (SRM) and $\mathrm{ESI}^{+}$ionization. All of the validated figures of merit were evaluated as satisfactory. Accuracy was assessed by recovery studies, varying from 82.7 to $115.5 \%$ for porcine kidney and from 91.5 to $110.4 \%$ for poultry kidney. Relative standard deviations were lower than $25.5 \%$ for porcine kidney, and $29.8 \%$ for poultry kidney. Decision limits (CC $\alpha$ ) comprised values from 10.37 to $3298.43 \mu \mathrm{g} \mathrm{kg}^{-1}$ for porcine kidney and 10.08 to $3176.59 \mu \mathrm{g} \mathrm{kg}^{-1}$ for poultry kidney. Detection capabilities $(\mathrm{CC} \beta)$ varied from 10.73 to $3396.86 \mu \mathrm{g} \mathrm{kg}^{-1}$ for porcine kidney and 10.67 to $3253.19 \mu \mathrm{g} \mathrm{kg}{ }^{-1}$ for poultry kidney. The developed method has been successfully employed in the routine analysis of incurred samples.
\end{abstract}

Keywords: mass spectrometry, chromatography, sample preparation

\section{Introduction}

The presence of residues of veterinary drugs in products of animal origin has been a constant concern for public health. ${ }^{1}$ Foodstuff derived from animals treated with the antibiotics fluoroquinolones (FQs) and sulfonamides may be contaminated with these drugs, which can lead to the development of allergic reactions or bacterial resistance in the consumers. ${ }^{2,3}$ Therefore, it is vital to monitor the presence of these residues in tissues derived from food producing animals.

Fluoroquinolones and sulfonamides are synthetic antimicrobial agents extensively used both in animals and humans. Trimethoprim is a synthetic diaminopyrimidine bacteriostatic which enhances the effect of some sulfonamides when associated with them. Their combined use has the advantage of a lower incidence of bacterial resistance and also a bactericidal effect. ${ }^{4,5}$

*e-mail: diego.lanagromg@gmail.com
According to the Regulation 37/2010 of the European Commission, ${ }^{6}$ fluoroquinolones, trimethoprim and sulfonamides, except dapsone, are veterinary drugs of permitted use with a reference limit (RL) equals to the established maximum residue limit (MRL). For kidney tissue, this value corresponds to $100 \mu \mathrm{g} \mathrm{kg}^{-1}$ for the sum of all sulfonamides, $50 \mu \mathrm{g} \mathrm{kg}^{-1}$ for trimethoprim, $150 \mu \mathrm{g} \mathrm{kg}^{-1}$ for oxolinic acid, $300 \mu \mathrm{g} \mathrm{kg}^{-1}$ for the sum between ciprofloxacin and enrofloxacin (200 $\mu \mathrm{g} \mathrm{kg}^{-1}$ for bovine), $800 \mu \mathrm{g} \mathrm{kg}^{-1}$ for difloxacin (600 $\mathrm{g} \mathrm{kg} \mathrm{k}^{-1}$ for poultry) and $400 \mu \mathrm{g} \mathrm{kg}^{-1}$ for danofloxacin. Dapsone has no MRL established for being included in Table 1 (prohibited substances) of the annex to Regulation (EC) No. 37/2010 because of insufficient data concerning reproductive toxicity and teratogenicity. However, there is no regulation that states an official recommended concentration for dapsone, e.g., there has not been set a minimum required performance limit (MRPL) for that substance, which is a tool for harmonization between laboratories that corresponds to the minimum content of an analyte in a sample that has to be detected and confirmed by 
official laboratories. In these cases, an internal laboratory protocol was followed and a recommended concentration of $10 \mu \mathrm{g} \mathrm{kg}^{-1}$ was adopted as RL during the validation. ${ }^{7}$ Another reference taken is the Codex Alimentarius, ${ }^{8}$ which establishes the MRL of $3000 \mu \mathrm{g} \mathrm{kg}^{-1}$ for flumequine, and $80 \mu \mathrm{g} \mathrm{kg}^{-1}$ for sarafloxacin for poultry kidney. For the other compounds for which there is no MRL reported, a reference limit of $10 \mu \mathrm{g} \mathrm{kg}^{-1}$ was chosen, according to an internal protocol of our laboratory. ${ }^{7}$

The extraction procedure was based on the QuEChERS (Quick, Easy, Cheap, Effective, Rugged and Safe) extraction approach, developed in 2003 by Anastassiades et al. ${ }^{9}$ for the extraction of pesticide residues from fruits and vegetables. The original method involves an extraction with acetonitrile, a liquid-liquid partition performed by the addition of anhydrous magnesium sulfate and sodium chloride, and dispersive solid phase extraction (d-SPE) using anhydrous magnesium sulfate and PSA (primary secondary amine). Various modifications to the original method have been proposed since then, ${ }^{10-13}$ and the present optimization of the extraction procedure for fluoroquinolones has already been reported in a previous work. ${ }^{14}$ The separation of the analytes is usually performed by high performance liquid chromatography (HPLC), and the detection is made by mass spectrometry using the electrospray ionization mode in the SRM mode (selected reaction monitoring). ${ }^{15}$ A noteworthy protocol was published by Stubbings and Bigwood, ${ }^{16}$ in which twelve FQs and 16 sulfonamides were extracted by a QuEChERS approach and analyzed by liquid chromatography-tandem mass spectrometry (LC-MS/MS) in poultry muscle, with recoveries varying from 40 to $93 \%$. Bittencourt et al. ${ }^{17}$ used a minimum sample preparation procedure using acetonitrile as extraction solvent to analyze eight FQs and nine sulfonamides in a screening method, for a false-compliant rate $<5 \%$ ( $\beta$ error) for poultry muscle samples. Lopes et al..$^{18}$ developed a QuEChERS extraction approach to the determination of two FQs, six sulfonamides and trimethoprim by LC-MS/MS, obtaining recoveries from 75.7 to $110.2 \%$.

The purpose of this work is the validation of a multiresidue methodology by LC-MS/MS to determine 12 fluoroquinolones, trimethoprim and 12 sulfonamides, including dapsone, which has not yet been validated together with the other compounds in poultry and porcine kidney. The validation was performed according to the Normative Instruction 24/2009-MAPA, ${ }^{19}$ which embraces the validation criteria present in the European Decision $657 / 2002 / \mathrm{EC}^{20}$ guidelines, e.g., the calculation of the

Table 1. Statistical results obtained for linearity and precision for porcine kidney samples

\begin{tabular}{|c|c|c|c|c|c|c|}
\hline Analyte & Intercept & Slope & $\mathrm{R}^{2}$ & $t$-value & $\mathrm{RSD}_{\text {intra-day }} / \%$ & $\mathrm{RSD}_{\text {inter-day }} / \%$ \\
\hline Ciprofloxacin & -0.005 & 0.001 & 0.929 & 7.24 & 4.25 & 8.3 \\
\hline Danofloxacin & 0.032 & 0.006 & 0.953 & 9.00 & 5.25 & 15.2 \\
\hline Dapsone & 0.002 & 0.008 & 0.918 & 4.62 & 1.30 & 25.5 \\
\hline Difloxacin & 0.040 & 0.028 & 0.983 & 15.38 & 9.81 & 13.8 \\
\hline Enrofloxacin & 0.018 & 0.020 & 0.966 & 10.67 & 6.65 & 12.5 \\
\hline Flumequine & 1.110 & 0.059 & 0.961 & 9.91 & 12.00 & 9.0 \\
\hline Marbofloxacin & 0.016 & 0.022 & 0.987 & 17.66 & 1.52 & 19.4 \\
\hline Nalidixic acid & 0.001 & 0.135 & 0.995 & 28.03 & 1.16 & 15.3 \\
\hline Norfloxacina & 0.002 & 0.013 & 0.979 & 13.76 & 1.51 & 24.4 \\
\hline Ofloxacin & 0.005 & 0.063 & 0.974 & 12.20 & 1.36 & 18.7 \\
\hline Oxolinic acid & -0.094 & 0.105 & 0.974 & 12.34 & 4.13 & 14.2 \\
\hline Pipemidic acid & 0.001 & 0.022 & 0.959 & 9.70 & 1.53 & 20.6 \\
\hline Sarafloxacin & 0.004 & 0.024 & 0.962 & 10.02 & 1.45 & 20.6 \\
\hline Sulfaclorpiridazine & 0.003 & 0.017 & 0.920 & 4.57 & 1.95 & 9.2 \\
\hline Sulfadiazine & 0.001 & 0.009 & 0.986 & 11.94 & 2.60 & 9.7 \\
\hline Sulfadimethoxine & 0.021 & 0.038 & 0.960 & 6.65 & 2.35 & 12.0 \\
\hline Sulfadoxine & 0.007 & 0.047 & 0.978 & 7.65 & 2.58 & 9.9 \\
\hline Sulfamerazine & 0.002 & 0.015 & 0.980 & 14.09 & 2.20 & 6.8 \\
\hline Sulfamethazine & 0.002 & 0.014 & 0.986 & 11.62 & 2.37 & 10.3 \\
\hline Sulfamethoxazole & 0.003 & 0.015 & 0.932 & 5.13 & 2.17 & 11.2 \\
\hline Sulfamethoxypyridazine & 0.003 & 0.022 & 0.992 & 15.94 & 1.95 & 8.0 \\
\hline Sulfaquinoxaline & 0.028 & 0.015 & 0.966 & 7.49 & 3.23 & 14.9 \\
\hline Sulfathiazole & 0.005 & 0.005 & 0.972 & 8.22 & 2.30 & 13.1 \\
\hline Sulfisoxazole & 0.001 & 0.004 & 0.924 & 4.83 & 3.18 & 10.6 \\
\hline Trimethoprim & 0.001 & 0.008 & 0.984 & 2.81 & 2.67 & 15.1 \\
\hline
\end{tabular}


decision limit $(\mathrm{CC} \alpha)$ and detection capability $(\mathrm{CC} \beta)$ for sample compliance issues.

\section{Experimental}

\section{Reagents and standards}

All reagents were of analytical grade. Glacial acetic acid was acquired from Tedia Brazil (Rio de Janeiro, Brazil) and formic acid was purchased from Impex (Diadema, Brazil). Anhydrous sodium acetate and sodium sulfate were acquired from Vetec (Rio de Janeiro, Brazil), and the dispersive phases PSA and C-18 were purchased from Varian (Amsterdam, Netherlands). The following HPLC grade solvents were used: methanol supplied by Panreac (Barcelona, Spain) and acetonitrile purchased from Merck (Darmstadt, Germany).

The fluoroquinolones standards, i.e., nalidixic acid was purchased from Acros Organics (New Jersey, USA); ciprofloxacin D8 (internal standard, IS) was purchased from CDN Isotopes (Quebec, Canada); ciprofloxacin, norfloxacin, ofloxacin, oxolinic acid and pipemidic acid were purchased from Sigma-Aldrich (St. Louis, USA); danofloxacin, difloxacin, enrofloxacin, flumequine, marbofloxacin and sarafloxacin were purchased from Dr. Ehrenstorfer (Augsburg, Germany). The sulfonamides standards, i.e., sulfadimethoxine, sulfaclorpiridazine, sulfadoxine and dapsone were acquired from SigmaAldrich (St. Louis, USA); sulfathiazole, sulfaquinoxaline, sulfadiazine, sulfisoxazole, sulfamethoxazole, sulfamethazine, sulfamiderazine, sulfamethoxypyridazine and sulfapyridine (IS) were purchased from Dr. Ehrenstorfer (Augsburg, Germany). Trimethoprim, tetracyclines standards (tetracycline, oxytetracycline, chlortetracycline, doxycycline, epitetracycline, epiclortetracycline and epioxytetracycline) and $\beta$-lactam antibiotics (ampicillin, cefazolin, oxacillin, penicillin $\mathrm{V}$ and penicillin $\mathrm{G}$ ) were purchased from Dr. Ehrenstorfer (Augsburg, Germany).

Ultrapure water generated by Gehaka, Master Sigma 100 (Gehaka, São Paulo, Brazil) was used. The $0.45 \mu \mathrm{m}$ nylon filter membranes Millex HN (Millipore, Billerica, USA) were used to filter the extracts before injection in the chromatographic system.

\section{Preparation of standard solutions}

Individual stock solutions of the sulfonamides and trimethoprim at a concentration of $250 \mu \mathrm{g} \mathrm{mL}^{-1}$ and fluoroquinolones at a concentration of $100 \mu \mathrm{g} \mathrm{mL}^{-1}$ were prepared by dissolving the exact mass of each compound in methanol. The solutions were stored at $-20{ }^{\circ} \mathrm{C}$.
Working solutions of the sulfonamides and trimethoprim were prepared by mixing the individual stock solutions and diluting them to a final concentration of $0.25,1.25$ and $2.50 \mu \mathrm{g} \mathrm{mL}^{-1}$ of dapsone, trimethoprim and other sulfonamides, respectively. Working solutions of the fluoroquinolones at $0.80 \mu \mathrm{g} \mathrm{mL} \mathrm{m}^{-1}$ were prepared by mixing the individual stock solutions. All working solutions were diluted with water:methanol $(80: 20, \mathrm{v} / \mathrm{v})$. All solutions were stored at $4{ }^{\circ} \mathrm{C}$.

Instrumentation

All experiments were performed with a triple quadrupole mass spectrometer with a turbo ion spray interface (API 5000, Applied Biosystems, Foster City, CA, USA) coupled to a HP Agilent Technologies 1200 series liquid chromatography system equipped with an autosampler and a quaternary pump (Agilent Technologies, Santa Clara, CA, USA). Both systems and data treatment were controlled by Analyst 1.5.1 software (Applied Biosystems, Foster City, CA, USA). Separation was achieved on an Eclipse XDB-C18 $(150 \times 4.6 \mathrm{~mm}, 5 \mu \mathrm{m})$ (Agilent Technologies, Waldbronn, Germany). The flow rate used was $0.600 \mathrm{~mL} \mathrm{~min}^{-1}$ and the column temperature was set at $30^{\circ} \mathrm{C}$. A gradient elution programmer was used with solvent $\mathrm{A}$ (aqueous solution with $0.1 \% \mathrm{v} / \mathrm{v}$ formic acid) and solvent B (acetonitrile with $0.1 \% \mathrm{v} / \mathrm{v}$ formic acid) as follows: from 0 to $3 \mathrm{~min}$ the percentage of solution B linearly increased from 10 to $20 \%$; from 3 to 6 min this percentage linearly increased to $50 \%$; from 6 to 8 min the solvent B percentage linearly increased to $80 \%$ and is maintained constant up to $9 \mathrm{~min}$; from 9 to 10 min the percentage of solution B decreased to $10 \%$, which was maintained up to $15 \mathrm{~min}$. The injection volume in the LC-MS/MS system was $5 \mu \mathrm{L}$. Mass analysis conditions optimized were achieved on infusion injection at a flow rate of $0.800 \mathrm{~mL} \mathrm{~min}^{-1}$. Each standard solution was prepared separately in methanol with $0.1 \% \mathrm{v} / \mathrm{v}$ formic acid at $50 \mathrm{ng} \mathrm{mL}^{-1}$. After optimization, the source block temperature was set at $700{ }^{\circ} \mathrm{C}$ in positive-ion mode with a capillary voltage of $5.5 \mathrm{kV}$. Nitrogen gas was used as a desolvation agent and nebulizer gas $\left(\mathrm{N}_{2}\right)$ at flow rates of $50 \mathrm{~L} \mathrm{~h}^{-1}$. Argon was used as the collision gas. Detection was operated in SRM mode.

\section{Sample preparation}

$2.0 \mathrm{~g}$ blank tissue were introduced into a $50 \mathrm{~mL}$ centrifuge tube, and directly spiked with an adequate volume of working solutions of the fluoroquinolones and sulfonamides. Ciprofloxacin D8 and sulfapyridine were used to obtain a concentration of 80 and $10 \mu \mathrm{g} \mathrm{kg}^{-1}$, 
respectively. The samples were left to stand in the dark for $30 \mathrm{~min}$ at room temperature.

A volume of $10 \mathrm{~mL}$ of acetonitrile acidified with $5 \%$ $\mathrm{v} / \mathrm{v}$ of glacial acetic acid was used as the extraction phase to poultry and porcine kidney. The samples were vortexed for $30 \mathrm{~s}$. Then, $4 \mathrm{~g}$ of sodium sulfate and $1 \mathrm{~g}$ of sodium acetate were added to the tubes. After vortexing for $30 \mathrm{~s}$, mixtures were centrifuged at $3810 \times \mathrm{g}(10 \mathrm{~min}) .1500 \mu \mathrm{L}$ of supernatants were transferred to Eppendorf tubes containing $50 \mathrm{mg}$ of a mixture of the dispersive phases (C18 and PSA 1:1 m/m), vortexed for $30 \mathrm{~s}$ and centrifuged again at $17968 \times \mathrm{g}$ for $20 \mathrm{~min}$ at $4{ }^{\circ} \mathrm{C}$. The extracts were evaporated in test tubes containing $100 \mu \mathrm{L}$ of ethylene glycol $10 \% \mathrm{v} / \mathrm{v}$ in methanol in a water bath at $40{ }^{\circ} \mathrm{C}$ using air flow. The extract is reconstituted to $2000 \mu \mathrm{L}$ with the first composition of the mobile phase gradient (acetonitrile: $\mathrm{H}_{2} \mathrm{O} 10 \% \mathrm{v} / \mathrm{v}$ with $0.1 \% \mathrm{v} / \mathrm{v}$ formic acid). The final extracts were filtered with a $0.45 \mu \mathrm{m}$ nylon membrane before injection in the LC-MS/MS system.

\section{Validation parameters}

Validation of the methods was performed according to the Normative Instruction 24/2009-MAPA, which is in accordance with EU guidelines and Codex Alimentarius. , $^{81,20}$ The validation parameters evaluated for porcine kidney samples were: linearity, accuracy, precision (intra- and inter-day), decision limit ( $\mathrm{CC} \alpha)$, detection capability $(\mathrm{CC} \beta)$, uncertainty and selectivity. This procedure was extended to poultry kidney samples, through a simplified approach (extension of the former validation to a different matrix), evaluating linearity, accuracy, precision (intra-day), $\mathrm{CC} \alpha, \mathrm{CC} \beta$ and uncertainty. ${ }^{19}$

\section{Linearity}

Internal standard calibration curves were prepared using the analyte peak area ratio by the internal standard versus analyte concentration. A concentration of $75 \mu \mathrm{g} \mathrm{kg}{ }^{-1}$ for sulfapyridine and $80 \mu \mathrm{g} \mathrm{kg}^{-1}$ for ciprofloxacin D8 was used for the IS. The five concentration levels were: $25,50,75$, 100 and $125 \mu \mathrm{g} \mathrm{kg}^{-1}$ for sulfonamides; 2.5, 5.0, 7.5, 10.0 and $12.5 \mu \mathrm{g} \mathrm{kg}^{-1}$ for dapsone; 25.0, 37.5, 50.0, 62.5 and $75.0 \mu \mathrm{g} \mathrm{kg}^{-1}$ for trimethoprim. Since the fluoroquinolones present different reference limits (Table 2), different calibration levels were used. For marbofloxacin, nalidixic acid, ofloxacin and pipemidic acid, the calibration levels were: $2.5,5.0,7.5,10.0$ and $12.5 \mu \mathrm{g} \mathrm{kg}^{-1}$. For sarafloxacin, the levels were: $20.0,40.0,60.0,80.0$ and $100.0 \mu \mathrm{g} \mathrm{kg}^{-1}$. For oxolinic acid the concentrations were 37.5, 75.0, 112.5, 150.0 and $187.5 \mu \mathrm{g} \mathrm{kg}^{-1}$. For ciprofloxacin and enrofloxacin the used concentrations were 75.0, 150.0, 225.0, 300 and $375 \mu \mathrm{g} \mathrm{kg}^{-1}$. The other tested levels were 100.0, 200.0, $300.0,400.0$ and $500.0 \mu \mathrm{g} \mathrm{kg}^{-1}$ for danofloxacin; 150.0 , $300.0,450.0,600.0$ and $750.0 \mu \mathrm{g} \mathrm{kg}^{-1}$ for difloxacin and 750.0, 1500.0, 2250.0, 3000.0 and $3750.0 \mu \mathrm{g} \mathrm{kg}^{-1}$ for flumequine. Six curves were prepared for porcine kidney, and three for poultry kidney. Linearity was evaluated for both porcine and poultry kidney by the Student's $t$-test and by the assessment of the determination coefficients obtained from the combination of all calibration curves constructed for each matrix. Six curves were prepared in six different occasions for porcine kidney, and three curves were prepared in three different days for poultry kidney, since the former matrix was validated through an extended approach. ${ }^{19}$ Each concentration level was injected three times in the chromatographic system.

\section{Accuracy and precision}

To evaluate accuracy, intra-day and inter-day precision, blank kidney samples were spiked with standards at three concentration levels: $0.50,1.00$ and 1.25 times the RL of each compound. The option for using 1.25 RL was made because a better linearity behavior was observed for the analytical curves for which this was the highest concentration, in comparison with the curves for which the more usual value of 1.50 RL was tested. The analyses were performed in six replicates per level. This procedure was executed on three different days by the same analyst for evaluation of the intra-day precision. To assess the inter-day precision, the same assays described earlier were performed by another analyst under the same conditions. Recoveries were calculated by interpolation of each analyte peak area ratio by the internal standard on the corresponding calibration curves. The calculated concentration was subsequently divided by the theoretical value. Precision were evaluated by relative standard deviation (RSD) in area for replicates at the RL level of each analyte.

\section{Decision limit, detection capability and uncertainty}

To calculate the $\mathrm{CC} \alpha$ and $\mathrm{CC} \beta$, kidney samples were prepared at three levels in sextuplicate: 2.5, 10.0 and $12.5 \mu \mathrm{g} \mathrm{kg}^{-1}$ for dapsone; $12.5,50.0$ and $62.5 \mu \mathrm{g} \mathrm{kg}^{-1}$ for trimethoprim; 25, 100 and $125 \mu \mathrm{g} \mathrm{kg}^{-1}$ for sulfonamides and $0.5,1.0$ and 1.25 RL for fluoroquinolones (the reference limits RLs are described in Tables 3 and 4). Each ratio between the analyte peak area by the IS area was interpolated on the corresponding calibration curves. This procedure was repeated for six different days for porcine kidney (inter-day precision), and three different 
Table 2. Individual recoveries obtained for each analyte at multiple concentrations of the adopted reference limits for accuracy assessment

\begin{tabular}{|c|c|c|c|c|c|c|}
\hline \multirow[t]{2}{*}{ Analyte } & \multicolumn{3}{|c|}{$\begin{array}{c}\text { Porcine kidney } \\
\text { Recovery / \% }\end{array}$} & \multicolumn{3}{|c|}{$\begin{array}{c}\text { Poultry kidney } \\
\text { Recovery / \% }\end{array}$} \\
\hline & $0.5 \mathrm{RL}$ & 1.0 RL & $1.25 \mathrm{RL}$ & $0.5 \mathrm{RL}$ & $1.0 \mathrm{RL}$ & $1.25 \mathrm{RL}$ \\
\hline Ciprofloxacin & 84.6 & 82.7 & 90.4 & 98.7 & 110.4 & 102.3 \\
\hline Danofloxacin & 94.7 & 96.1 & 102.8 & 95.6 & 110.0 & 109.5 \\
\hline Dapsone & 89.7 & 95.3 & 96.4 & 90.4 & 95.0 & 101.9 \\
\hline Difloxacin & 90.5 & 92.9 & 105.7 & 92.6 & 100.6 & 108.9 \\
\hline Enrofloxacin & 95.9 & 102.0 & 104.8 & 102.6 & 109.3 & 110.1 \\
\hline Flumequine & 83.0 & 84.7 & 92.7 & 99.7 & 97.4 & 95.4 \\
\hline Marbofloxacin & 110.3 & 109.0 & 102.1 & 96.5 & 109.7 & 102.6 \\
\hline Nalidixic acid & 88.2 & 95.9 & 90.6 & 91.7 & 104.5 & 98.5 \\
\hline Norfloxacina & 97.1 & 105.7 & 101.5 & 98.2 & 97.8 & 102.3 \\
\hline Ofloxacin & 92.3 & 97.2 & 101.9 & 92.9 & 91.5 & 102.4 \\
\hline Oxolinic acid & 89.3 & 99.6 & 105.6 & 101.1 & 107.1 & 93.5 \\
\hline Pipemidic acid & 101.7 & 115.5 & 91.9 & 93.2 & 101.7 & 95.5 \\
\hline Sarafloxacin & 97.6 & 101.2 & 105.8 & 92.2 & 106.3 & 105.4 \\
\hline Sulfaclorpiridazine & 105.1 & 99.6 & 96.4 & 107.2 & 103.1 & 102.0 \\
\hline Sulfadiazine & 105.5 & 101.1 & 98.7 & 107.6 & 103.6 & 102.7 \\
\hline Sulfadimethoxine & 106.6 & 101.0 & 98.6 & 109.1 & 106.9 & 107.8 \\
\hline Sulfadoxine & 108.6 & 101.5 & 96.2 & 109.6 & 104.7 & 101.5 \\
\hline Sulfamerazine & 105.6 & 100.2 & 97.9 & 108.7 & 102.0 & 101.8 \\
\hline Sulfamethazine & 106.8 & 101.1 & 100.3 & 109.4 & 103.8 & 102.5 \\
\hline Sulfamethoxazole & 107.1 & 102.0 & 104.6 & 107.5 & 106.3 & 101.9 \\
\hline Sulfamethoxypyridazine & 106.3 & 100.5 & 99.6 & 107.1 & 103.5 & 102.4 \\
\hline Sulfaquinoxaline & 107.3 & 94.3 & 96.5 & 102.3 & 93.4 & 98.8 \\
\hline Sulfathiazole & 109.4 & 102.8 & 101.5 & 104.1 & 102.5 & 106.6 \\
\hline Sulfisoxazole & 107.2 & 102.4 & 103.8 & 106.2 & 107.5 & 108.1 \\
\hline Trimethoprim & 102.2 & 99.9 & 93.1 & 92.3 & 96.6 & 89.2 \\
\hline
\end{tabular}

RL: Reference limit.

days for poultry kidney (intra-day precision). CC $\alpha$ was determined as the concentration at the MRL (or reference limit, RL) level plus 1.64 times of the standard deviation at this level, taken as $10 \mu \mathrm{g} \mathrm{kg}^{-1}$ for dapsone, $50 \mu \mathrm{g} \mathrm{kg}^{-1}$ for trimethoprim, $100 \mu \mathrm{g} \mathrm{kg}^{-1}$ for sulfonamides and the different reference limits adopted for each fluoroquinolones listed on Tables 3 and 4. CC $\beta$ was calculated as the concentration at the decision limit plus 1.64 times of the standard deviation of the inter-day precision.

The estimated uncertainty of the method was assessed using a combination between the top-down and bottom-up methodologies, taking into account the influences of the calibration curves used during the validation experiments and relative standard deviation from the precision evaluation. ${ }^{19}$

\section{Selectivity}

In order to evaluate the selectivity of method, standard solutions of $\beta$-lactam antibiotics (ampicillin, cefazolin, oxacillin, penicillin $\mathrm{V}$ and penicillin $\mathrm{G}$ ) and tetracyclines (tetracycline, oxytetracycline, chlortetracycline, doxycycline, epitetracycline, epiclortetracycline and epioxytetracycline) were added to the samples fortified with dapsone, trimethoprim, sulfonamides and fluoroquinolones. The tetracyclines and $\beta$-lactam antibiotics were chosen due to the history of positive samples containing these antibiotics together with sulfonamides and fluoroquinolones. The porcine kidney samples were spiked at $600 \mu \mathrm{g} \mathrm{kg}^{-1}$ for tetracyclines and $300 \mu \mathrm{g} \mathrm{kg}^{-1}$ for $\beta$-lactam antibiotics at each recovery level for dapsone ( $0.5,1$ and 2 times of the MRL), trimethoprim, sulfonamides and fluoroquinolones $(0.5,1$ and 1.25 times of the MRL). Nine samples contaminated with tetracyclines and $\beta$-lactam antibiotics, three at each level, in a total of eighteen samples were therefore analyzed.

\section{Results and Discussion}

Optimization of chromatographic and spectrometric conditions

The composition of the mobile phase, the gradient elution program, the flow rate and the temperature of the column were optimized to obtain the best peak resolution 
Table 3. $\mathrm{CC} \alpha$ and $\mathrm{CC} \beta$ values obtained for porcine and poultry kidney samples

\begin{tabular}{|c|c|c|c|c|c|}
\hline \multirow{2}{*}{ Analyte } & \multirow{2}{*}{$\mathrm{RL} /\left(\mu \mathrm{g} \mathrm{kg}^{-1}\right)$} & \multicolumn{2}{|c|}{ Porcine kidney } & \multicolumn{2}{|c|}{ Poultry kidney } \\
\hline & & $\mathrm{CC} \alpha /\left(\mu \mathrm{g} \mathrm{kg}^{-1}\right)$ & $\mathrm{CC} \beta /\left(\mu \mathrm{g} \mathrm{kg}^{-1}\right)$ & $\mathrm{CC} \alpha /\left(\mu \mathrm{g} \mathrm{kg}^{-1}\right)$ & $\mathrm{CC} \beta /\left(\mu \mathrm{g} \mathrm{kg}^{-1}\right)$ \\
\hline Ciprofloxacin & 300 & 333.91 & 352.82 & 327.80 & 355.59 \\
\hline Danofloxacin & 400 & 445.27 & 470.54 & 444.11 & 488.21 \\
\hline Dapsone & 10 & 10.37 & 10.73 & 10.08 & 10.67 \\
\hline Difloxacin & 600 & 704.69 & 789.38 & 662.47 & 684.95 \\
\hline Enrofloxacin & 300 & 322.54 & 345.07 & 337.26 & 374.52 \\
\hline Flumequine & 3000 & 3298.43 & 3396.86 & 3176.59 & 3253.19 \\
\hline Marbofloxacin & 10 & 13.78 & 17.56 & 12.03 & 14.07 \\
\hline Nalidixic acid & 10 & 12.40 & 14.8 & 11.22 & 12.44 \\
\hline Norfloxacin & 10 & 14.05 & 15.11 & 11.12 & 12.25 \\
\hline Ofloxacin & 10 & 13.05 & 16.10 & 12.23 & 14.54 \\
\hline Oxolinic acid & 150 & 183.50 & 191.00 & 168.89 & 187.78 \\
\hline Pipemidic acid & 10 & 13.86 & 17.72 & 11.42 & 12.84 \\
\hline Sarafloxacin & 80 & 83.45 & 86.91 & 81.18 & 82.36 \\
\hline Sulfaclorpiridazine & 100 & 106.61 & 113.22 & 103.89 & 107.78 \\
\hline Sulfadiazine & 100 & 102.04 & 104.07 & 102.84 & 105.67 \\
\hline Sulfadimethoxine & 100 & 103.83 & 107.66 & 103.48 & 106.96 \\
\hline Sulfadoxine & 100 & 103.64 & 107.27 & 104.93 & 109.86 \\
\hline Sulfamethazine & 100 & 102.06 & 104.11 & 103.86 & 107.73 \\
\hline Sulfamethoxazole & 100 & 105.77 & 111.53 & 105.15 & 110.29 \\
\hline Sulfamethoxypyridazine & 100 & 101.08 & 102.17 & 101.20 & 102.41 \\
\hline Sulfamiderazine & 100 & 101.38 & 102.77 & 101.37 & 102.74 \\
\hline Sulfathiazole & 100 & 103.13 & 106.25 & 103.13 & 106.26 \\
\hline Sulfisoxazole & 100 & 106.21 & 112.42 & 106.43 & 112.86 \\
\hline Sulphaquinoxaline & 100 & 100.93 & 101.85 & 101.15 & 102.30 \\
\hline Trimethoprim & 50 & 55.59 & 61.17 & 52.60 & 55.20 \\
\hline
\end{tabular}

RL: Reference limit; $C C \alpha$ : decision limits; $C C \beta$ : detection capabilities.

and a reduced chromatography run time. Figure 1 shows the chromatogram of a porcine kidney sample extracted and analyzed under the optimized conditions, described in Instrumentation section. Identification of the analytes might be achieved according to the retention times listed on Table 5.

The SRM mode was employed monitoring one transition for quantification and one transition for identification of each analyte. This selection took into account the intensity and the stability of the signal related to the monitored ions. The maximum permitted tolerances between the confirmation and the quantification transitions areas (ion ratio) or intensities for any suspicious sample should fell within the tolerance criteria established by the Comission Decision 657, when compared to a spiked sample or reference material, in order to confirm the presence of a given analyte. This decision clearly specified the maximum deviation between the observed and the expected ion ratios, by setting relative ion abundance tolerance windows for ion abundance ratios in the mass spectra of particular substance.

The selected transitions, the relative intensity between them (ion ratios), and the declustering potential (DP), collision energies (CE), and retention times of the analytes (RT) are shown in Table 5. The first product ion displayed for each precursor ion corresponds to the quantification transition, and the second product ion to the confirmation transition.

\section{Validation}

\section{Linearity}

Homoscedasticity of the variances related to the instrumental response was evaluated through the $\mathrm{F}$ test. The calculated F-values were higher than the critical F-value, thus the weighted least squares method (WLS) was employed, using the inverse of the variance as weight at each calibration level. The identification of outliers was performed by applying the Grubbs' test. The intercept and slope of the internal standard calibration curves, the coefficients of determination $\left(\mathrm{R}^{2}\right)$ and $t$-values calculated at the 95\% confidence level are shown in Tables 1 and 6 for porcine kidney and poultry kidney samples, respectively. For porcine kidney, the lowest $\mathrm{R}^{2}$ value was 0.918 for dapsone and the highest $\mathrm{R}^{2}$ value was 0.995 for nalidixic 
Table 4. Uncertainty obtained for porcine and poultry kidney samples at the reference limit (RL) of each analyte

\begin{tabular}{|c|c|c|c|}
\hline \multirow[b]{2}{*}{ Analyte } & \multirow{2}{*}{$\begin{array}{c}\mathrm{RL} / \\
\left(\mu \mathrm{g} \mathrm{kg}^{-1}\right)\end{array}$} & \multicolumn{2}{|c|}{ Uncertainty / \% } \\
\hline & & $\begin{array}{l}\text { Porcine } \\
\text { kidney }\end{array}$ & $\begin{array}{l}\text { Poultry } \\
\text { kidney }\end{array}$ \\
\hline Ciprofloxacin & 300 & 18.03 & 38.69 \\
\hline Danofloxacin & 400 & 11.13 & 20.25 \\
\hline Dapsone & 10 & 37.80 & 34.80 \\
\hline Difloxacin & 600 & 10.28 & 10.10 \\
\hline Enrofloxacin & 300 & 17.07 & 30.53 \\
\hline Flumequine & 3000 & 4.50 & 5.06 \\
\hline Marbofloxacine & 10 & 52.20 & 28.10 \\
\hline Nalidixic acid & 10 & 61.90 & 40.40 \\
\hline Norfloxacin & 10 & 56.80 & 21.80 \\
\hline Ofloxacin & 10 & 56.60 & 70.30 \\
\hline Oxolinic acid & 150 & 26.03 & 43.00 \\
\hline Pipemidic acid & 10 & 83.70 & 32.60 \\
\hline Sarafloxacin & 80 & 9.26 & 2.95 \\
\hline Sulfaclorpiridazine & 100 & 11.27 & 7.83 \\
\hline Sulfadiazine & 100 & 13.44 & 15.41 \\
\hline Sulfadimethoxine & 100 & 20.38 & 11.21 \\
\hline Sulfadoxine & 100 & 14.02 & 12.99 \\
\hline Sulfamerazine & 100 & 10.29 & 9.54 \\
\hline Sulfamethazine & 100 & 12.20 & 11.00 \\
\hline Sulfamethoxazole & 100 & 13.62 & 12.53 \\
\hline Sulfamethoxipiridazine & 100 & 11.13 & 7.53 \\
\hline Sulfaquinoxaline & 100 & 24.58 & 23.07 \\
\hline Sulfathiazole & 100 & 22.27 & 10.66 \\
\hline Sulfisoxazole & 100 & 17.26 & 18.99 \\
\hline Trimethoprim & 50 & 22.50 & 26.38 \\
\hline
\end{tabular}

acid. For poultry kidney, the lowest $\mathrm{R}^{2}$ value was 0.944 for danofloxacin and the highest $\mathrm{R}^{2}$ value was 0.998 for pipemidic acid. The calculated $t$-values were higher than critical $t$-value (2.78) indicating a linear behavior of the curves.

\section{Precision and accuracy}

Acceptance criteria for precision comprised RSD values lower than $30 \%$ for mass fractions from 1 to $10 \mu \mathrm{g} \mathrm{kg}^{-1}, 20 \%$ from 10 to $100 \mu \mathrm{g} \mathrm{kg}^{-1}, 15 \%$ from 100 to $1000 \mu \mathrm{g} \mathrm{kg}^{-1}$ and $10 \%$ above $1000 \mu \mathrm{g} \mathrm{kg}^{-1} .{ }^{8}$ According to Tables 1 and 6, all the RSD values obtained fell within this established range. ${ }^{4}$ For porcine kidney, the $\mathrm{RSD}_{\text {inter-day }}$ varied from $6.8 \%$ for sulfamerazine and $25.5 \%$ for dapsone. As for poultry kidney the $\mathrm{RSD}_{\text {intra-day }}$ values varied from $5.3 \%$ for ciprofloxaxin and $29.8 \%$ for dapsone.

Acceptance criteria for accuracy comprised recovery percentages in the ranges $60-120 \%$ for concentrations up to $10 \mu \mathrm{g} \mathrm{kg}^{-1}, 70-120 \%$ to $100 \mu \mathrm{g} \mathrm{kg}^{-1}$ and $70-110 \%$ to concentrations above $1000 \mu \mathrm{g} \mathrm{kg}^{-1} .8$ Table 2 presents the individual recoveries calculated at the respective multiples of the referent limits validated (0.5, 1.0 and $1.25 \mathrm{RL})$. The individual reference limits are listed on Table 3 . For porcine kidney recoveries varied from $82.7 \%$ for ciprofloxacin, which seems to be so due to the inferior quality of fit adjustment (goodness-of-fit) presented for that analyte in that specific case, and $115.5 \%$ for pipemidic acid. For poultry kidney recoveries comprised the range from $91.5 \%$

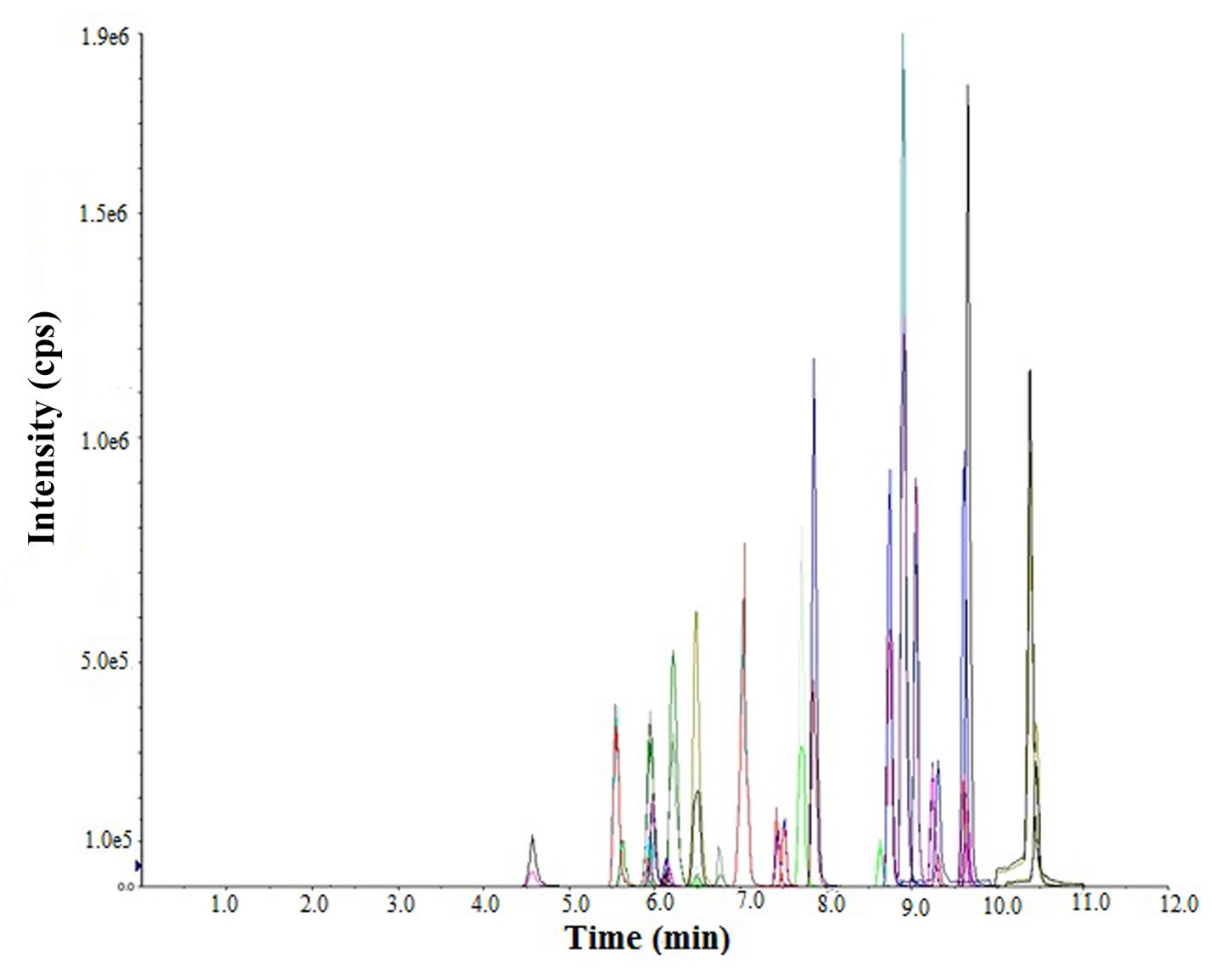

Figure 1. Total ion chromatogram of a porcine kidney sample spiked at $100 \mu \mathrm{g} \mathrm{kg} \mathrm{g}^{-1}$ obtained from LC-MS/MS. 
Table 5. Data acquisition used in the analyzes by the SRM mode

\begin{tabular}{|c|c|c|c|c|c|c|}
\hline Analyte & Precursor ion & Product ion & Ion ratio / \% & $\mathrm{DP} / \mathrm{V}$ & $\mathrm{CE} / \mathrm{V}$ & $\mathrm{RT} / \mathrm{min}$ \\
\hline Ciprofloxacin & 332.0 & $\begin{array}{l}314.0 \\
231.0\end{array}$ & 90.4 & 60 & $\begin{array}{l}40 \\
35\end{array}$ & 5.60 \\
\hline Ciprofloxacin D8 (IS) & 340.2 & $\begin{array}{l}296.3 \\
249.0\end{array}$ & 72.1 & 65 & $\begin{array}{l}22 \\
33\end{array}$ & 6.39 \\
\hline Danofloxacin & 358.3 & $\begin{array}{c}82.1 \\
255.0\end{array}$ & 26.6 & 130 & $\begin{array}{l}50 \\
33\end{array}$ & 6.76 \\
\hline Dapsone & 249.2 & $\begin{array}{l}108.0 \\
156.0\end{array}$ & 133.4 & 96 & 19 & 8.83 \\
\hline Difloxacin & 400.1 & $\begin{array}{l}356.0 \\
299.3\end{array}$ & 112.4 & 21 & $\begin{array}{l}29 \\
37\end{array}$ & 7.65 \\
\hline Enrofloxacin & 360.2 & $\begin{array}{l}316.2 \\
245.2\end{array}$ & 172.1 & 51 & $\begin{array}{l}37 \\
40\end{array}$ & 7.01 \\
\hline Flumequine & 262.3 & $\begin{array}{l}244.2 \\
202.3\end{array}$ & 82.3 & 126 & $\begin{array}{l}21 \\
43\end{array}$ & 10.54 \\
\hline Marbofloxacin & 363.0 & $\begin{array}{c}72.0 \\
320.0\end{array}$ & 28.7 & 40 & $\begin{array}{l}32 \\
28\end{array}$ & 5.89 \\
\hline Nalidixic acid & 233.2 & $\begin{array}{l}215.2 \\
187.0\end{array}$ & 140.0 & 31 & $\begin{array}{l}21 \\
35\end{array}$ & 10.47 \\
\hline Norfloxacin & 320.2 & $\begin{array}{l}276.3 \\
233.2\end{array}$ & 85.8 & 51 & $\begin{array}{l}25 \\
33\end{array}$ & 6.20 \\
\hline Ofloxacin & 362.4 & $\begin{array}{l}261.0 \\
318.0\end{array}$ & 79.3 & 60 & $\begin{array}{l}33 \\
23\end{array}$ & 6.32 \\
\hline Oxolinic acid & 262.1 & $\begin{array}{l}244.2 \\
216.0\end{array}$ & 23.2 & 66 & $\begin{array}{l}23 \\
39\end{array}$ & 9.41 \\
\hline Pipemidic acid & 304.0 & $\begin{array}{l}217.0 \\
189.0\end{array}$ & 29.4 & 120 & $\begin{array}{l}25 \\
35\end{array}$ & 4.68 \\
\hline Sarafloxacin & 386.2 & $\begin{array}{l}342.1 \\
299.0\end{array}$ & 123.0 & 21 & $\begin{array}{l}29 \\
37\end{array}$ & 7.58 \\
\hline Sulfaclorpiridazine & 285.2 & $\begin{array}{c}156.0 \\
92.1\end{array}$ & 53.8 & 26 & $\begin{array}{l}23 \\
33\end{array}$ & 8.82 \\
\hline Sulfadiazine & 251.0 & $\begin{array}{c}156.2 \\
92.1\end{array}$ & 105.1 & 46 & $\begin{array}{l}17 \\
31\end{array}$ & 6.21 \\
\hline Sulfadimethoxine & 311.2 & $\begin{array}{l}156.0 \\
245.5\end{array}$ & 8.0 & 106 & $\begin{array}{l}31 \\
23\end{array}$ & 9.84 \\
\hline Sulfadoxine & 310.9 & $\begin{array}{c}153.3 \\
92.1\end{array}$ & 70.6 & 21 & $\begin{array}{l}23 \\
43\end{array}$ & 9.00 \\
\hline Sulfamerazine & 265.1 & $\begin{array}{c}92.0 \\
156.1\end{array}$ & 101.0 & 66 & $\begin{array}{l}37 \\
25\end{array}$ & 7.20 \\
\hline Sulfamethazine & 279.0 & $\begin{array}{l}124.0 \\
186.0\end{array}$ & 52.3 & 51 & 29 & 7.92 \\
\hline Sulfamethoxazole & 254.1 & $\begin{array}{c}108.0 \\
92.0\end{array}$ & 123.6 & 60 & 35 & 9.23 \\
\hline Sulfamethoxypyridazine & 281.0 & $\begin{array}{l}156.0 \\
126.0\end{array}$ & 34.9 & 86 & 25 & 8.01 \\
\hline Sulfapyridine (IS) & 250.0 & $\begin{array}{l}156.1 \\
184.3\end{array}$ & 63.7 & 41 & $\begin{array}{l}23 \\
25\end{array}$ & 6.70 \\
\hline Sulfaquinoxaline & 301.0 & $\begin{array}{l}156.0 \\
118.1\end{array}$ & 6.9 & 106 & $\begin{array}{l}23 \\
39\end{array}$ & 9.72 \\
\hline Sulfathiazole & 256.1 & $\begin{array}{c}156.0 \\
92.3\end{array}$ & 72.9 & 31 & $\begin{array}{l}21 \\
37\end{array}$ & 6.40 \\
\hline Sulfisoxazole & 268.5 & $\begin{array}{l}113.2 \\
156.3\end{array}$ & 91.0 & 41 & 21 & 9.40 \\
\hline Trimethoprim & 291.5 & $\begin{array}{l}123.1 \\
230.1\end{array}$ & 106.0 & 21 & $\begin{array}{l}37 \\
39\end{array}$ & 5.82 \\
\hline
\end{tabular}

DP: Declustering potential; CE: collision energies; RT: retention times of the analytes. 
Table 6. Statistical results obtained for linearity and precision for poultry kidney samples

\begin{tabular}{|c|c|c|c|c|c|}
\hline Analyte & Intercept & Slope & $\mathrm{R}^{2}$ & $t$-value & $\mathrm{RSD}_{\text {intra-day }} / \%$ \\
\hline Ciprofloxacin & 0.009 & 0.014 & 0.971 & 11.56 & 5.3 \\
\hline Danofloxacin & 0.017 & 0.029 & 0.944 & 8.18 & 6.3 \\
\hline Dapsone & 0.001 & 0.007 & 0.983 & 3.96 & 29.8 \\
\hline Difloxacin & 0.027 & 0.021 & 0.994 & 25.08 & 6.6 \\
\hline Enrofloxacin & 0.003 & 0.017 & 0.977 & 12.92 & 7.0 \\
\hline Flumequine & 1.479 & 0.051 & 0.994 & 24.95 & 5.9 \\
\hline Marbofloxacin & 0.001 & 0.031 & 0.997 & 36.01 & 11.5 \\
\hline Nalidixic acid & 0.000 & 0.153 & 0.994 & 25.88 & 7.2 \\
\hline Norfloxacina & -0.002 & 0.012 & 0.981 & 14.28 & 7.0 \\
\hline Ofloxacin & 0.015 & 0.042 & 0.951 & 8.79 & 15.3 \\
\hline Oxolinic acid & 0.013 & 0.126 & 0.991 & 20.71 & 7.1 \\
\hline Pipemidic acid & 0.000 & 0.008 & 0.998 & 46.33 & 9.0 \\
\hline Sarafloxacin & 0.006 & 0.015 & 0.990 & 19.83 & 6.2 \\
\hline Sulfaclorpiridazine & 0.005 & 0.022 & 0.978 & 9.45 & 10.3 \\
\hline Sulfadiazine & 0.001 & 0.009 & 0.986 & 12.03 & 10.0 \\
\hline Sulfadimethoxine & 0.030 & 0.045 & 0.977 & 9.06 & 9.7 \\
\hline Sulfadoxine & 0.008 & 0.053 & 0.971 & 8.07 & 9.9 \\
\hline Sulfamerazine & 0.003 & 0.016 & 0.984 & 14.55 & 6.4 \\
\hline Sulfamethazine & 0.003 & 0.013 & 0.980 & 9.76 & 12.6 \\
\hline Sulfamethoxazole & 0.005 & 0.019 & 0.970 & 8.03 & 11.8 \\
\hline Sulfamethoxypyridazine & 0.004 & 0.022 & 0.992 & 15.8 & 7.1 \\
\hline Sulfaquinoxaline & 0.014 & 0.017 & 0.988 & 12.54 & 17.8 \\
\hline Sulfathiazole & 0.008 & 0.014 & 0.979 & 9.59 & 12.9 \\
\hline Sulfisoxazole & 0.001 & 0.005 & 0.957 & 6.57 & 10.3 \\
\hline Trimethoprim & 0.002 & 0.011 & 0.969 & 7.81 & 19.2 \\
\hline
\end{tabular}

$\mathrm{R}^{2}$ : Coefficients of determination.

for ofloxacin and 110.4 for ciprofloxacin. It can be noticed that all recoveries fell within the established criteria.

\section{Decision limit and detection capability}

As recommended by the European Decision 657/2002/ $\mathrm{EC},{ }^{20}$ the $\mathrm{CC} \alpha$ was used to define the limit above which it can be concluded that a sample contains the analyte, with an error probability of $\alpha$ equals to 5\% (probability of false non-compliant decision). The CC $\beta$ was also assessed, which is the lowest concentration of a compound that may be detected, identified and quantified in a sample, with an error probability of $\beta$ equals to $5 \%$ (probability of falsecompliant results). From the calibration curves constructed for the spiked samples during the experiments for precision assessment, six experiments for porcine kidney and three for poultry kidney, the values of the decision limits and detection capabilities for all analytes are shown in Table 3. In practical terms, when the reported concentration is lower than $\mathrm{CC} \alpha$, the sample can be considered compliant (the analyte is absent or present in a concentration lower than the MRL) with a confidence level of $(1-\alpha)$. The critical value of $C C \beta$ refers to the concentration above which it can be concluded that the analyte is unambiguously present, for forbidden substances, or present at a concentration higher than the MRL in the case of regulated substances. Therefore, a sample can be declared non-compliant (when a prohibited analyte is confirmed or a permitted analyte is present at a concentration higher than the MRL) if its reported concentration is higher than $\mathrm{CC} \beta$, with a confidence level of $(1-\beta)$. For a concentration range between $C C \alpha$ and $\mathrm{CC} \beta$ the result statistically remains unclassified, and it is dependent on the internal protocol of each institution. Due to this compliance issue, it is recommended that $\mathrm{CC} \alpha$ and $\mathrm{CC} \beta$ values lie on the same order of the magnitude of the MRL or the recommended concentration. ${ }^{6,20}$

\section{Uncertainty}

Although uncertainty's measurement was not explicitly mentioned in Decision 2002/657/EC, the Normative Instruction 24/2009-MAPA recognizes its embracement, since it is a clear requirement of the ISO/IEC 17025 standard. A composition between the bottom-up and top-down strategies ${ }^{19}$ was used for uncertainty assessment, considering two main sources: the uncertainty related to the calculation of each analyte concentration obtained from 
the calibration curves constructed during validation, and the uncertainty derived from the precision experiments (inter-day for porcine and intra-day for poultry kidney). These two variabilities were combined and multiplied by a coverage factor of two in order to give an overall figure for the uncertainty of the measurement. The presented values of uncertainty presented in percent relative basis were calculated at the respective reference limit of each analyte. For porcine kidney uncertainties varied between $4.50 \%$ for flumequine and $83.70 \%$ for pipemidic acid, and for poultry kidney the values varied between $2.95 \%$ for sarafloxacin and $70.30 \%$ for ofloxacin (Table 4). As expected, the analytes presenting lower RLs $\left(10 \mu \mathrm{g} \mathrm{kg}^{-1}\right)$ exhibited the highest uncertainties percentage values. For compliance issues when the uncertainty measurement is to be applied, a non-compliant sample would be the one for which the calculated concentration is higher than the sum between the reference limit, e.g., MRL, and the reported uncertainty.

\section{Selectivity}

The selectivity of the method was demonstrated by comparing the analytes recoveries with the addition of $\beta$-lactams and tetracyclines as potential interfering agents. The recoveries (with and without addition) were compared by the F test and Student's $t$-test at $95 \%$ significance level, to ascertain whether the addition of such compounds significantly affects the detection of the evaluated analytes. All the $t$-values calculated were lower than the critical $t$-value $\left(t_{(0.05,16)}: 2.12\right)$, varying from 0.09 to 0.99 for porcine kidney. Therefore, good selectivity is proved for the extraction and detection of fluoroquinolones and sulfonamides in kidney, when together with the studied interfering compounds.

\section{Conclusions}

This work presents the validation of a LC-MS/MS multiresidue method for the simultaneous identification and quantification of 25 compounds among fluoroquinolones, sulfonamides and trimethoprim in poultry and porcine kidney. The extraction procedure is based on a QuEChERS approach, which is able to provide good extraction efficiency together with low consumption of supplies and short analysis time. The validation followed the Normative Instruction 24/2009-MAPA guidelines. The developed method has officially been implemented in laboratory routine for the analysis of incurred samples at LANAGROMG, proving to be suitable through standardized control protocols and satisfactory results obtained in proficiency tests.

\section{Acknowledgments}

The authors would like to thank the Ministério da Agricultura, Pecuária e Abastecimento for the infrastructure support. We would also like to acknowledge the Fundação de Amparo à Pesquisa do Estado de Minas Gerais (project FAPEMIG CEX - APQ-00586-12), the Pró-Reitoria de Pesquisa da Universidade Federal de Minas Gerais (public edict PRPq - 01/2013) and the Coordenação de Aperfeiçoamento de Pessoal de Nível Superior (CAPES) for their financial support.

\section{References}

1. Stolker, A. A. M.; Zuidema, T.; Nielen, M. W. F.; Trends Anal. Chem. 2007, 26, 967.

2. Committee for Medicinal Products for Veterinary Use (CVMP); Public Statement on the Use of (Fluoro)Quinolones in FoodProducing Animals in the European Union: Development of Resistance and Impact on Human and Animal Health; European Medicines Agency (EMA), London, 15 February 2007.

3. Kantiani, L.; Llorca, M.; Sanchis, J.; Farré, M.; Barceló, D.; Anal. Bioanal. Chem. 2010, 398, 2413.

4. Economou, A.; Petraki, O.; Tsipi, D.; Botitsi, E.; Talanta 2012, 97, 32.

5. Spinosa, H. S.; Bernardi, M. M.; Gorniak, S. L.; Farmacologia Aplicada à Medicina Veterinária, 5a ed.; Guanabara Koogan: São Paulo, Brazil, 2011, p. 848.

6. European Commision; Commision Regulation (EU) No. 37/2010 of 22 December 2009 on Pharmacologically Active Substances and Their Classification Regarding Maximum Residue Limits in Foodstuffs of Animal Origin; Official Journal, 2010, L 15, p. 1.

7. Ministério da Agricultura, Pecuária e Abastecimento (MAPA); Secretaria de Defesa Agropecuária; Instrução Normativa No. 13, de 15 de Julho de 2015; Diário Oficial da União: Brasília, 2015.

8. Codex Alimentarius; Maximum Residue Limits (MRLs) and Risk Management Recommendations (RMRs) for Residues of Veterinary Drugs in Foods: CAC/MRL 2-2015; Geneva, Switzerland, 2015.

9. Anastassiades, M.; Lehotay, S. J.; Stajnbaher, D.; Schenck, F. J.; J. AOAC Int. 2003, 86, 412.

10. Lehotay, S. J.; J. AOAC Int. 2007, 90, 485.

11. Lehotay, S. J.; de Kok, A.; Hiemstra, M.; Van Bodegraven, P.; J. AOAC Int. 2005, 88, 595.

12. Moreno-Bondi, M. C.; Marazuela, M. D.; Herranz, S.; Rodríguez, E.; Anal. Bioanal. Chem. 2009, 395, 921.

13. Marazuela, M. D.; Bogialli, S.; Anal. Chim. Acta 2009, 645, 5.

14. Rocha, D. G.; Santos, F. A.; da Silva, J. C. C.; Augusti, R.; Faria, A. F.; J. Chromatogr. A 2015, 1379, 83. 
15. Malik, A. K.; Blasco, C.; Picó, Y.; J. Chromatogr. A 2010, 1217, 4018.

16. Stubbings, G.; Bigwood, T.; Anal. Chim. Acta 2009, 637, 68.

17. Bittencourt, M. S.; Martins, M. T.; de Albuquerque, F. G. S.; Barreto, F.; Hoff, R.; Food Addit. Contam., Part A 2012, 29, 508.

18. Lopes, R. P.; Reyes, R. C.; Romero-González, R.; Frenich, A. G.; Vidal, J. L.; Talanta 2012, 89, 201.

19. Secretaria de Defesa Agropecuária. Instrução Normativa No. 24, de 14 de julho de 2009; Anexo II: Guia de Validação de Métodos Analíticos e Controle de Qualidade Interna de
Análises de Monitoramento de Plano Nacional de Resíduos e Contaminantes - PNCRC Animal; Diário Oficial da União de 22/07/2009, Seção 1 , p. 7.

20. European Commission; 2002/657/EC: Commission Decision of 12 August 2002 Implementing Council Directive 96/23/EC Concerning the Performance of Analytical Methods and the Interpretation of Results; Official Journal, 2002, L 221, p. 8.

Submitted: December 22, 2015

Published online: May 10, 2016 